•论坛・

\title{
阿尔泰山中蒙边境地区的雪豹及其保护意义
}

\author{
初雯雯 ${ }^{1}$ 蒋志刚 ${ }^{2,4}$ 李 凯 $^{1}$ 胡德夫 ${ }^{1^{*}}$ 陈 刚 $^{3}$ 初红军 $^{3}$ \\ 1 (北京林业大学生态与自然保护学院, 北京 100083) \\ 2 (中国科学院动物研究所, 北京 100101) \\ 3 (新疆卡拉麦里山有蹄类野生动物自然保护区管理中心, 乌鲁木齐 830000) \\ 4 (中国科学院大学生命科学学院, 北京 100049)
}

\section{The snow leopard in Altai Mountains, near the Sino-Mongolia border, and its conservation significance}

\author{
Wenwen $\mathrm{Chu}^{1}$, Zhigang Jiang ${ }^{2,4}$, Kai $\mathrm{Li}^{1}$, Defu $\mathrm{Hu}^{1 *}$, Gang $\mathrm{Chen}^{3}$, Hongjun $\mathrm{Chu}^{3}$ \\ 1 School of Ecology and Nature Conservation, Beijing Forestry University, Beijing 100083 \\ 2 Institute of Zoology, Chinese Academy of Sciences, Beijing 100101 \\ 3 Management Center, Mt. Kalamaili Ungulate Nature Reserve, Urumqi 830000 \\ 4 College of Life Sciences, University of Chinese Academy of Sciences, Beijing 100049
}

雪豹(Panthera uncia) 是猫科豹亚科动物, 生活 在林线以上的高山带和亚高山带。据全球雪豹及其 生态系统保护计划 (Global Snow Leopard \& Ecosystem Protection Program, GSLEP)估计, 目前 全球雪豹为4,000-6,500 只, 其分布跨越 12 个国家, 分布面积约为 180 万 $\mathrm{km}^{2}$, 其中 $60 \%$ 以上在中国 (Snow Leopard Working Secretariat, 2013, https://www. globalsnow leopard.org/)。雪豹分布在高海拔陡峭偏 远的山地环境, 种群密度低(Xu et al, 2008), 行踪论 秘，加之其烟灰色的花纹易于融入周围的裸岩环境， 限制了雪豹研究的开展。

位于中国新疆北部的阿尔泰山脉是全球重要 生态区“阿尔泰一萨彦生态区”的重要组成部分 (https://www.millenniumassessment.org/en/Multiscale. html), 也是具有全国性意义的陆地生物多样性关键 地区。沿着海拔梯度, 阿尔泰山跨越了温带荒漠、 戈壁、低山丘陵、中山温带森林、亚高山针叶林(泰 加林)、高山草甸和高山裸岩地带, 是雪豹分布区的 北界。

在新疆, 雪豹主要分布在昆仑山山脉、天山山
脉和阿尔泰山山脉(马鸣, 2013)。近年来已在昆仑山 脉、天山山脉发现了雪豹, 但在中国境内的阿尔泰 山区并未发现过雪豹实体(马鸣, 2013), 仅在阿勒泰 地区北塔山发现过两处雪豹抓痕(马鸣等, 2005)。尽 管已发现北山羊(Capra sibirica) 等在中蒙边界区域 阿尔泰山低山乃至荒漠的小型山脉栖息，而北山羊 是雪豹的主要食物, 但对于这里雪豹种群状况的了 解近乎空白。目前也仍不清楚雪豹在中国分布的北 界具体在哪里。

\section{雪豹在中国的分布北界}

2013-2019年, 我们在中国阿尔泰山开展了国 家科技基础性专项“阿勒泰中俄哈蒙边境特有动物 与动物地理区系考察”。在2013-2016年的野外监测 中, 在喀纳斯国家级自然保护区沿海拔梯度安放的 红外相机没有拍摄到雪豹(崔绍朋等, 2020), 在两河 源国家级自然保护区的考察中也未发现雪豹。2016 年4月到11月中旬, 我们在位于阿尔泰山东部中蒙 边境高山、亚高山和丘陵区的蒙其克、马哈萨提、 萨尔布拉克以及喀拉加勒克布设了16台红外相机，

收稿日期: 2019-03-25; 接受日期: 2019-07-25

基金项目: 国家重点研发计划(2016YFC0503303)、中国科学院战略性先导科技专项(XDA23080101)、国家科技基础性专项(2013FY110300)和新疆国际 科技合作项目(20136026-2)

* 通讯作者 Author for correspondence. E-mail: hudf@bjfu.edu.cn 
监测以雪豹和北山羊为旗舰种的中蒙边境地区动 物多样性。2016年9月30日, 在阿尔泰山东部的喀拉 加勒克 $\left(46^{\circ} 13^{\prime} 33^{\prime \prime} \mathrm{N}, 90^{\circ} 52^{\prime} 9^{\prime \prime} \mathrm{E}\right.$, 海拔1,497 m)拍摄 到一只雪豹(图1)。这是首次在阿尔泰山中国一侧拍 摄到雪豹清晰照片，也是雪豹在中国分布区的最北 端拍摄到的雪豹。同时, 在这里还拍摄到了北山羊, 证实阿尔泰山东部中蒙边境亚高山和低山区是雪 豹的重要栖息地，也是世界雪豹的西北分布区。

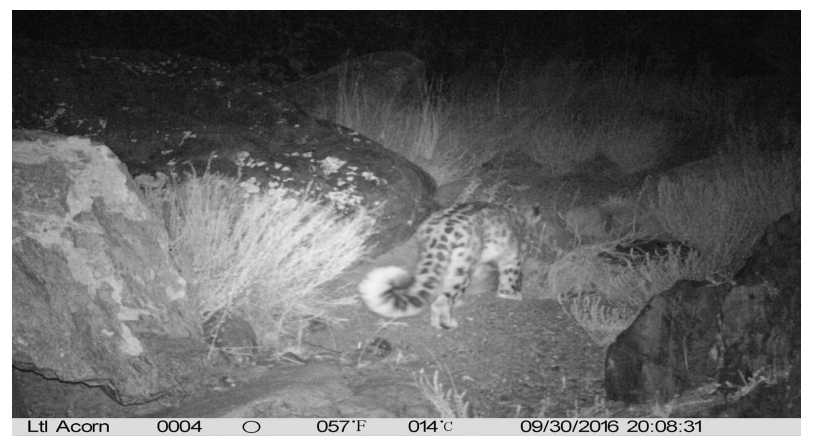

图1 在阿尔泰山东部中蒙边境喀拉加勒克首次拍摄到雪豹 Fig. 1 Snow leopard (Panthera uncia) first trapped by infrared camera at Kalajialeke in Altai Mountains, near the Sino-Mongolia border

\section{物种分布区极点的意义}

物种分布极点界定了物种的分布区(Hardie \& Hutchings, 2010), 对于生物地理学(Gaston, 2003)和 红色名录研究中确定物种占有区(area of occupancy) 和物种发生区 (area of occurrence) 具有重要意义 (https://www.iucnredlist.org)。一个国家对其境内分 布的濒危物种保护具有主体责任(蒋志刚等, 2020)。 物种分布区极点范围内的生物地理因素影响物种 分布区动态和物种形成, 从而决定了针对该物种的 保护对策。尽管我们尚不清楚雪豹分布区中环境、 生态和进化因素是如何限制雪豹活动范围的, 但由 于国境边界线铁丝围栏的阻隔, 该发现地点的雪豹 种群是一个边缘种群。物种的边缘种群往往会偏离 核心分布区, 表现出较低的遗传多样性或更强的环 境适应力。一个物种的边缘种群对于保护种内多样 性可能具有特殊价值, 同时也面临着较高的随机灭 绝风险(Hardie \& Hutchings, 2010)。

\section{3 该分布点对雪豹保护的意义}

该雪豹分布地点位于《保护野生动物迁徙物种
公约》(Convention on the Conservation of Migratory Species of Wild Animals)划定的中亚11号迁徙野生 动物关键地点与关键迁徙通道一阿尔泰山地 (https://www.cms.int/en/document/mapping-transboun dary-hotspots-central-asian-mammals-initiative) 位 于 中国-哈萨克斯坦-蒙古国-俄罗斯边境地区。包括 中国新疆维吾尔自治区阿勒泰地区, 哈萨克斯坦东 部省雷蒙贝克区，蒙古国Uvs和Bayan Ulgii Aimags, 以及俄罗斯联邦阿尔泰共和国Kosh-Agach区、图瓦 共和国的Buryatiya地区的阿尔泰山中部和东南部 $\left(47^{\circ} 41^{\prime}-49^{\circ} 04^{\prime} \mathrm{N}, 87^{\circ} 24^{\prime}-89^{\circ} 51^{\prime} \mathrm{E}\right.$ 。除雪豹外, 这一 该发现地点列入 《保护野生动物迁徙物种公约》附 录的迁徙物种还有盘羊(Ovis ammon)。

《保护野生动物迁徙物种公约》估计哈萨克斯 坦的雪豹数量不超过 10 只, 俄罗斯阿尔泰-萨彦地 区可能有70-90只。阿尔泰-萨彦地区仅发现分散的 雄性雪豹, 很少或没有繁殖的雌性雪豹(徐峰等, 2006), 这里雪豹的生存依赖于生境连接性、种群扩 散和重新定居的机会。位于我们此次雪豹发现地点 西南的蒙古阿尔泰地区被认为是雪豹种群密度较 高的地区(https://www.cms.int/en/document/mappingtransboundary-hotspots-central-asian-mammals-initiative)。

雪豹作为中亚山地的旗舰物种, 其保护价值不 言而喻。阿尔泰-萨彦地区特别是Saylyugem山脉及 其国家公园对雪豹和盘羊具有重要的保护意义。该 雪豹分布点及其种群构成了雪豹西北分布区的重 要组成部分。然而, 由于跨越4个国家, 该关键地区 雪豹种群受边界铁丝围栏和中国境内人类活动与 放牧区的阻隔，与雪豹主要分布区的连通度差。边 境围栏阻隔了雪豹及其主要食物盘羊的季节性迁 徙, 隔离了它们的生境甚至直接导致盘羊死亡。同 时雪豹还面临盗猎压力。例如盗猎分子曾在盐池湾 保护区盗猎雪豹, 扒下毛皮后掩埋, 巡山的森林公 安仅发现了掩埋的胴体, 因猫科动物形态相似而无 法鉴定结案, 最后利用特定的分子标记物才鉴定出 被盗猎的是雪豹(Zhang et al, 2007), 说明雪豹盗猎 曾一度十分猖獗。此外, 雪豹还面临分布区内牲畜 数量增加、栖息地退化、潜在疾病传播、潜在的工 业矿业发展以及人类与雪豹冲突等威胁 (马鸣, 2013)。

放牧和农田耕作是导致雪豹栖息地丧失的主 要原因(Jackson, 2014)。放牧也是影响雪豹栖息地选 
择的主要因素之一, 在牧区和非牧区两种生境中, 雪豹倾向于在非牧区活动。在中蒙边境地区，除紧 靠边境线的禁区外，其他区域均有放牧。一些牧场 已开始耕作，并建成了“无鼠害示范区”，使得当地 的自然生态系统产生了巨大变化(徐峰等, 2006)。

《保护野生动物迁徙物种公约》倡议建立蒙 古、俄罗斯、哈萨克斯坦和中国之间的阿尔泰跨界 生物圈保护区, 还建立了“中亚迁徙物种保护倡 议”(Central Asia Migratory Species Initiative, CAMI) 国家合作架构, 开展跨界迁徙物种保护学术交流。 该倡议提出在跨界迁徙野生动物热点地区开展详 细考察, 确定阿尔泰山野生动物迁徙国际通道范围; 加强跨境合作，保护跨国迁徙动物; 拆除或降低边 境地区关键地点的边界围栏; 管理家畜放牧; 加大 反偷猎力度; 修订盘羊战利品狩猎(Trophy Hunting) 方案，以确保当地社区有效参与跨国迁徙动物保护, 直接造福当地社区和自然保育。

保护雪豹这一大型迁徙物种需要全球行动, 大 部分保护机构仅有能力在特定地理范围或特定种 群层面上开展工作，而物种的灭绝风险却是在全球 尺度进行评估的。因此, 要填补这一尺度断层, 有 必要汇总各方面的工作, 加强各个雪豹种群与栖息 地保护(李小雨等, 2019)。建议持续开展监测, 以明 晰该区域雪豹种群现状及动态变化。同时, 通过与 蒙古国雪豹研究团队进行交流，必要时开展跨国界 的联合调查, 查明我国境内阿尔泰山尤其是中蒙边 境区域雪豹的生存现状和濒危原因，以期逐步恢复 阿尔泰山的雪豹种群。

致谢：端肖楠、吴兵、任松柏、甄荣、杜聪聪、阿 依丁、蒙克、白硕、蒋新春、李斌等参加野外数据 收集工作，新疆布尔根河狸国家级自然保护区管理 局马尔哈别克、毛玉平和金格斯等给予大力支持与 帮助，谨致衷心感谢!

\section{参考文献}

Cui SP, Chen DQ, Wang JY, Sun JZ, Chu HJ, Li CW, Jiang ZG (2020) Camera-trapping survey of mammals and birds in Kanas River Valley of Altai Mountains, Xinjiang. Biodiversity Science, 28, 435-441. (in Chinese with English abstract) [崔绍朋, 陈代强, 王金宇, 孙吉舟, 初红军, 李 春旺, 蒋志刚 (2020) 新疆阿尔泰山喀纳斯河谷鸟兽物
种的红外相机监测. 生物多样性, 28, 435-441.]

Gaston KJ (2003) The Structure and Dynamics of Geographic Ranges. Oxford University Press, Oxford and New York.

Hardie DC, Hutchings JA (2010) Evolutionary ecology at the extremes of species' ranges. Environmental Reviews, 18, 1-20.

Jackson R, Mallon D, Mishra C, Noras S, Sharma R, Suryawanshi K (2014) Snow Leopard Survival Strategy. Snow Leopard Network, Seattle.

Jiang ZG, Jiang JP, Wang YZ, Zhang E, Zhang YY, Cai B (2020) Significance of the country red lists of endangered species for biodiversity conservation. Biodiversity Science, 28, 10.17520/biods.2020149. (in Chinese with English abstract) [蒋志刚，江建平，王跃招，张鹗，张雁云，蔡波 (2020) 国家濒危物种红色名录的生物多样性保护意义. 生物多 样性, 28, 10.17520/biods.2020149.]

Li XY, Xiao LY, Liang XC, Cheng C, Feng C, Zhao X, Liu YL, Bian XX, He B, Zhang CZ, Alexander JS, Xing R, Huang $\mathrm{YH}$, Awangjiumei, Xierannima, Song DZ, Huang QW, Zhaxisange, Peng K, Yin H, Lian XM, Yang X, Li S, Shi XG, Yang CM, Lü Z (2019) Ongoing threats and the current status of snow leopard conservation in China. Biodiversity Science, 27, 932-942. (in Chinese with English abstract) [李小雨, 肖凌云, 梁旭昶, 程琛, 冯琛, 赵翔, 刘炎林, 市晓星, 何兵, 张常智, Alexander JS, 邢睿, 黄亚慧, 阿 旺久美, 谢然尼玛, 宋大昭, 黄巧雯, 扎西桑俄, 彭奎, 尹杭，连新明，杨欣，李晟，施小刚，杨创明，吕植 (2019) 中国雪豹的威胁与保护现状. 生物多样性, 27, 932-942.]

Ma M (2013) Snow Leopards in Xinjiang. Science Press, Beijing. (in Chinese) [马鸣 (2013) 新疆雪豹. 科学出版 社, 北京.]

Ma M, Munkhtsog B, Xu F, Mardan T, Yin SJ, Wei SD (2005) Markings as indicator of snow leopard in field survey, Xinjiang. Chinese Journal of Zoology, 40(4), 34-39. (in Chinese with English abstract) [马鸣, Munkhtsog B, 徐峰, 买尔旦，殷守敬，魏顺德 (2005) 新疆雪豹调查中的痕迹 分析. 动物学杂志, 40(4), 34-39.]

Xu A, Jiang Z, Li C, Guo J, Da S, Cui Q, Yu S, Wu G (2008) Status and conservation of snow leopard in East Burhanbuda Mountain, Kunlun Mountains, China. Oryx, 42, 460-463.

Xu F, Ma M, Yin SJ, Munkhtsog B (2006) Autumn habitat selection by snow leopard (Uncia uncia) in Beita Mountain, Xinjiang, China. Zoological Research, 27, 221-224. (in Chinese with English abstract) [徐峰，马鸣，殷守敬， Munkhtsog B (2006) 新疆北塔山雪豹对秋季栖息地的选 择. 动物学研究, 27, 221-224.]

Zhang F, Jiang Z, Zeng Y, McCarthy T (2007) Development of primers to characterize the mitochondrial control region of snow leopard (Uncia uncia). Molecular Ecology Notes, 7, 1196-1198.

(责任编委：吕植 责任编辑：周玉荣) 